\title{
An Experimental Study of Bending Behaviour of Double Channel and Hollow Sections of Light Gauge Steel
}

\author{
Sabril Haris", Andrey Prasetio", Rendy Thamrin", Hazmal Herman ${ }^{\#}$ \\ ${ }^{\#}$ Department of Civil Engineering, Andalas University, Kampus Unand Limau Manis, Padang, 25163, Indonesia \\ E-mail: sabril_haris_hg@ft.unand.ac.id, andreyprasetio@gmail.com,rendy@ft.unand.ac.id, hazmalherman@ymail.com
}

\begin{abstract}
This paper presents experimental results of the double channel and hollow sections of light gauge steel carrying a bending moment on their strong axis. The double channel sections were built from two channels which were joined using sufficient screws to form two combination models, i.e., Box Model (DC-Box) and Back to Back Model (DC-I). Bending behavior of five beam specimens: two specimens of Hollow Section, two specimens of DC-Box, and one specimen of DC-I, have been observed when they were subjected to two point loads which increased monotonically. It was found that the Hollow Section and DC-Box had the same failure model when they reached the ultimate load, i.e., permanent local buckling. Buckling occurred on top flange and web of the section, and the structures lost their resistance significantly. Meanwhile, elastic lateral torsional buckling prevented the DC-I specimen reached the higher load. The experimental results were compared to an analytical calculation based on the formula in the codes. Material properties obtained from tensile tests were used in the calculation. Comparison between the experimental data and the analytical results showed discrepancies within the range $18 \%-59 \%$. Based on this study, it is suggested a lower beam capacity of bending to obtain a conservative design of the structures.
\end{abstract}

Keywords — bending behavior; double channel and hollow sections; ultimate condition; local buckling; lateral torsional buckling.

\section{INTRODUCTION}

Light gauge steel has become an alternative material for building constructions in the recent years. The main advantages of this material are lightweight, high strength and stiffness, and simple erection and installation [1]. Research on light gauge steel material and its application to the residential building have been conducted by many researchers [2]-[4]. However, the material is so far commonly applied to the roof trusses where axial forces are dominant on the elements; the use of this material for the structures carrying bending moment is still rare.

The light gauge steel sections are generally made as an open section by folding a thin sheet, about $1 \mathrm{~mm}$ thickness or less, under the room temperature [1]. This open and thin section is vulnerable to both local and global buckling, and the weakness becomes more significant if the section is used for the beam subjected to the bending moment.

Experimental tests and numerical works on the local and global stability of light gauge steel single channel section subjected to bending moment have been reported [5]-[9]. The data of bending capacity obtained from the studies were compared to the formula in some codes. It was found from the tests that the failure initiated by distortional buckling gave higher strength reduction factor than the failure initiated by local buckling [5]. A numerical study was conducted in [6] to produce numerous virtual experimental data with the variation on a dimension of the cross-section, member length, and material grade. Uniform moment on the strong axis was applied to the unrestrained lip channel beams. From this study, it was proposed to modify moment capacity design equation in the Australian/New Zealand and North American design codes to obtain more conservative results. In [7], bending capacity of lipped channel beam considering local and global instabilities interactions was investigated. A design equation for nearly same local and distortional moments was proposed based on the comparison of numerical analysis and Direct Strength Method. Moreover, an experimental test which considered the effect of temperature and use of web stiffener was carried out and reported in [8]. Based on 42 specimen tests, inelastic bending capacity of cold-formed steel channel sections was analyzed and predicted in [9].

Improving buckling resistance of the light gauge section have been carried out using some alternatives, e.g., by adding timber or timber laminas to the channel section and double channel sections in back-to-back position ([10]-[12]). Axial load was applied to the composite sections with a variable length of compression elements. A significant increment in compressive load capacity was found for the short members, but less for the longer ones [12]. 
In this study, the channel section was joined to obtain a better section property for local and global stabilities. The first combination was two channel sections which were placed face-to-face and formed a box section. The second ones were placed back-to-back and formed I-section. The main difference between two combinations was that the box section becomes a closed section while the I-section remain an open section. The hollow section which was an initially closed section was also tested for comparison to the box section. The specimens were not laterally restrained along its span which was different to experimental tests of back-toback of double channel sections reported in [13].

Experimental tests were carried out to examine bending behavior of the combined sections and the hollow section. Type of ultimate conditions when the maximum load reached were observed. The experimental results were compared to the analytical calculation using formula in the codes.

\section{MATERIAL AND METHOD}

The simple beam specimens of double channels and hollow section were tested in this study. The original channel section was $75 \mathrm{~mm}$ height, $35 \mathrm{~mm}$ width and 0.75 $\mathrm{mm}$ thickness. Double channel sections were built from two channels which were joined using sufficient screws to form two combination models: Box Model (DC-Box) and Back to Back Model (DC-I). The self-drilling screws were placed on the section flanges of DC-Box and drilled onto the web for DC-I model. The hollow section was $70 \mathrm{~mm}$ height, $40 \mathrm{~mm}$ width and $0.65 \mathrm{~mm}$ thickness. The cross-section of the beams and their section properties are given in Fig. 1.

The behavior of five beam specimens: two specimens of Hollow Section, two specimens of DC-Box, and one specimen of DC-I, have been observed when they were subjected to two point loads which increased monotonically. The schematic diagram for loading test is shown in Fig. 2. The clear beam's span was $1200 \mathrm{~mm}$, and the distance between two point loads was $430 \mathrm{~mm}$. Thus, the shear span length was $385 \mathrm{~mm}$. A rigid steel spreader beam was used to obtain two equal point loads from a $500 \mathrm{kN}$ capacity hydraulic jack. The beam specimens were placed at two pin supports which the vertical and lateral displacements were restrained both.

The instantaneous load from the hydraulic jack was measured by using a load cell. LVDTs measured vertical displacement at mid-span and one of the point loads. A data logger was used to record the load and displacements data from the load cell and the LVDTs, respectively. This experimental setup was similar to the test arrangement conducted in [14]. Because the equipment's weight was significant to the beam specimens, the weight of all equipment which was placed above the specimen will be added later to the total maximum load to determine the bending capacity of the beam.

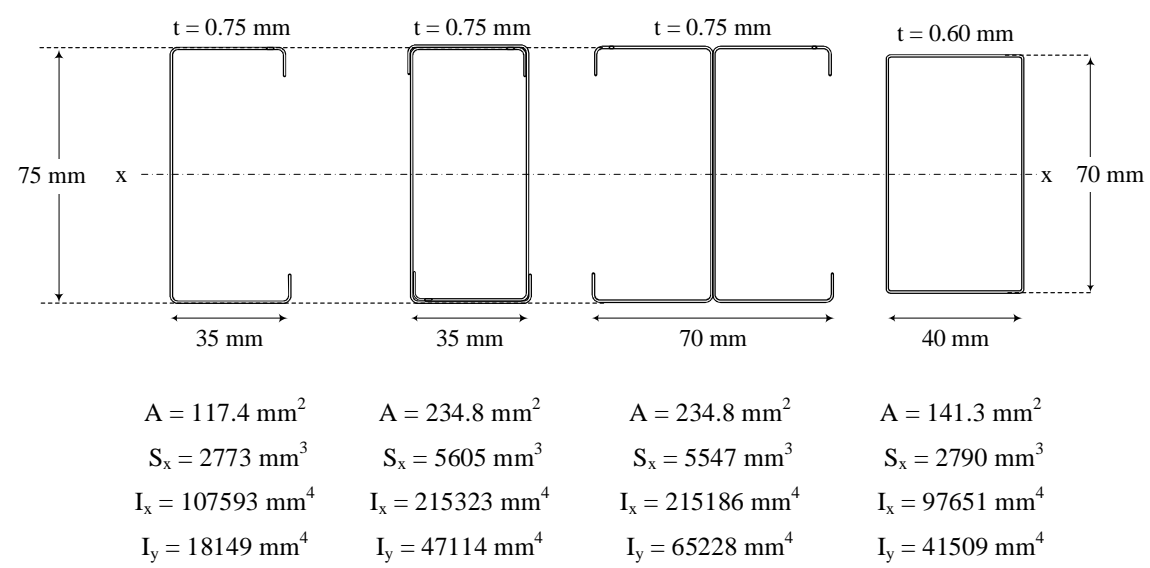

(a)

(b)

(c)

(d)

Fig. 1 Beam Cross Sections and section properties of (a) Original Lip Channel, (b) DC-Box, (c) DC-I and (d) Hollow

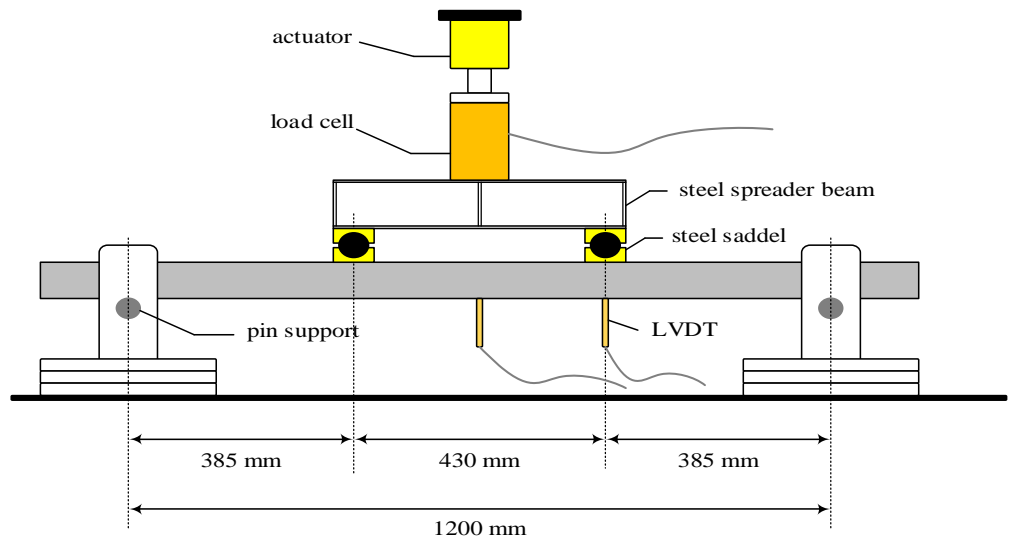

Fig. 2 The schematics diagram for the experimental test 


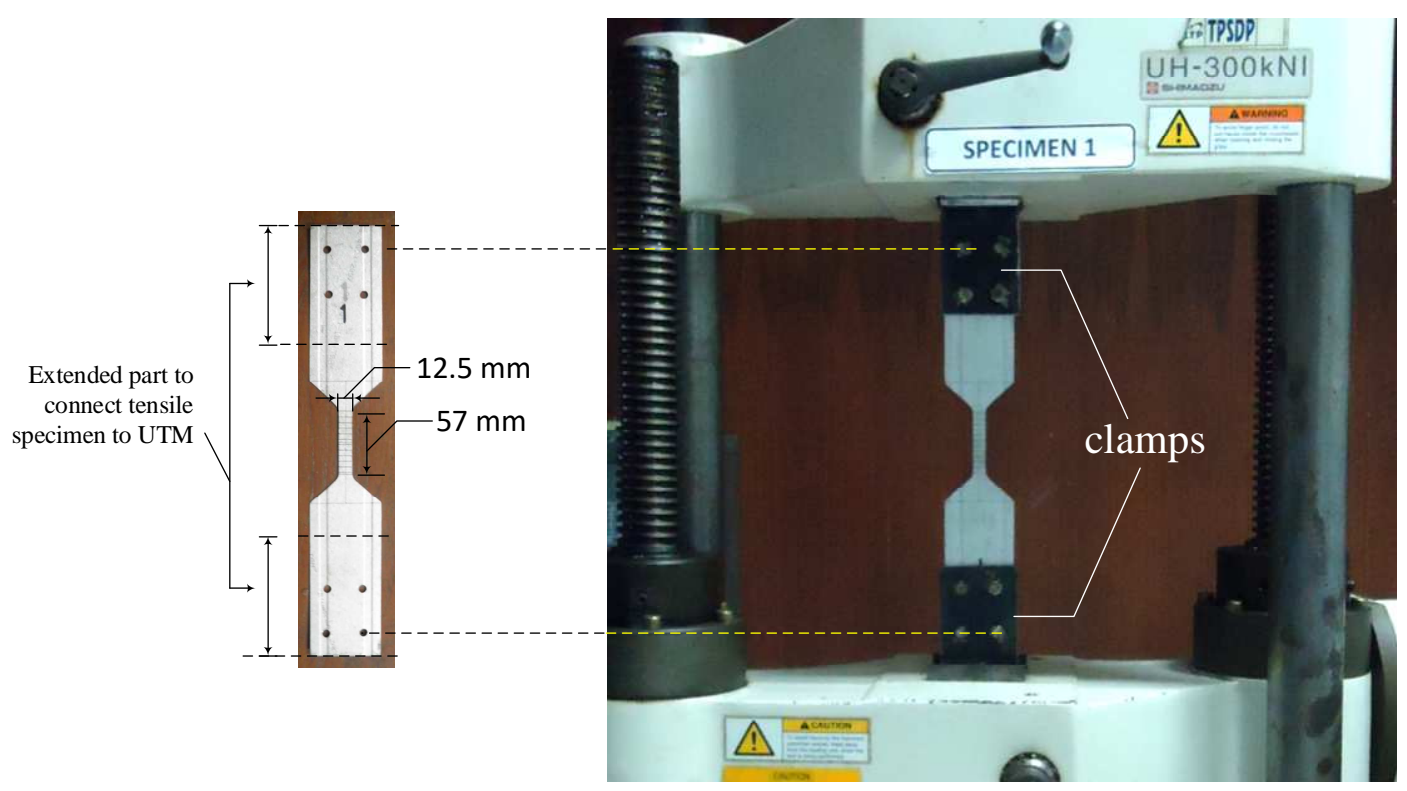

Fig. 3 The tensile specimen was cut from the web of channel section (left) and connected to the UTM through the clamps (right)

Material properties for each specimen were examined under tensile test which refers to ASTM Standards for Metals Test [14]. Tensile specimens were cut from web part of the channel and the hollow sections. The tensile length was $57 \mathrm{~mm}$, and the width was $12.5 \mathrm{~mm}$. Both ends of the specimen were connected to clamps, and further, the clamps were pulled by Universal Testing Machine (Fig. 3). The specimen was subjected to a static monotonic load with a constant speed of $2 \mathrm{~mm}$ per minute.

TABLE I

MATERIAL PROPERTIES

\begin{tabular}{|c|c|c|}
\hline Specimen & $\begin{array}{c}\text { Yield Stress } \\
\text { (MPa) }\end{array}$ & $\begin{array}{c}\text { Ultimate } \\
\text { Stress (MPa) }\end{array}$ \\
\hline DC-Box & 526.1 & 531.0 \\
\hline DC-I & 572.5 & 573.0 \\
\hline Hollow & 579.9 & 580.5 \\
\hline
\end{tabular}

The tensile test results are shown in Table 1. It was observed that the material had no significant strain hardening after yield point, and rupture occurred on the tensile specimens at the small strain (less than 5\%). The ratio between the yield and ultimate stress for all specimens was almost unity. Modulus of elasticity was assumed to be 200,000 MPa.

\section{RESULT AND DISCUSSION}

\section{A. Experimental Results}

Two types of ultimate conditions of the beam were observed from the tests, i.e. permanent local buckling and elastic lateral buckling. DC-Boxes and Hollow's section had the same failure of permanent local buckling, see Fig. 4. Local buckling occurred on the top flange and the web of the section located under the steel saddle. The top flange was dented early, and later, by increasing the load, the web was buckled inward-outward consecutively.

Buckling on the web can be observed from the curved meshing line. The damage was localized on the buckling zone while the other sections of the beam were almost unchanged. After buckling occurred on the web, the beam lost its resistance significantly. The hydraulic jack still worked after this point to obtain the post-buckling capacity of the beam. When the load was totally removed from the specimen, the beam was still bent which deflected point was in the buckling zone.
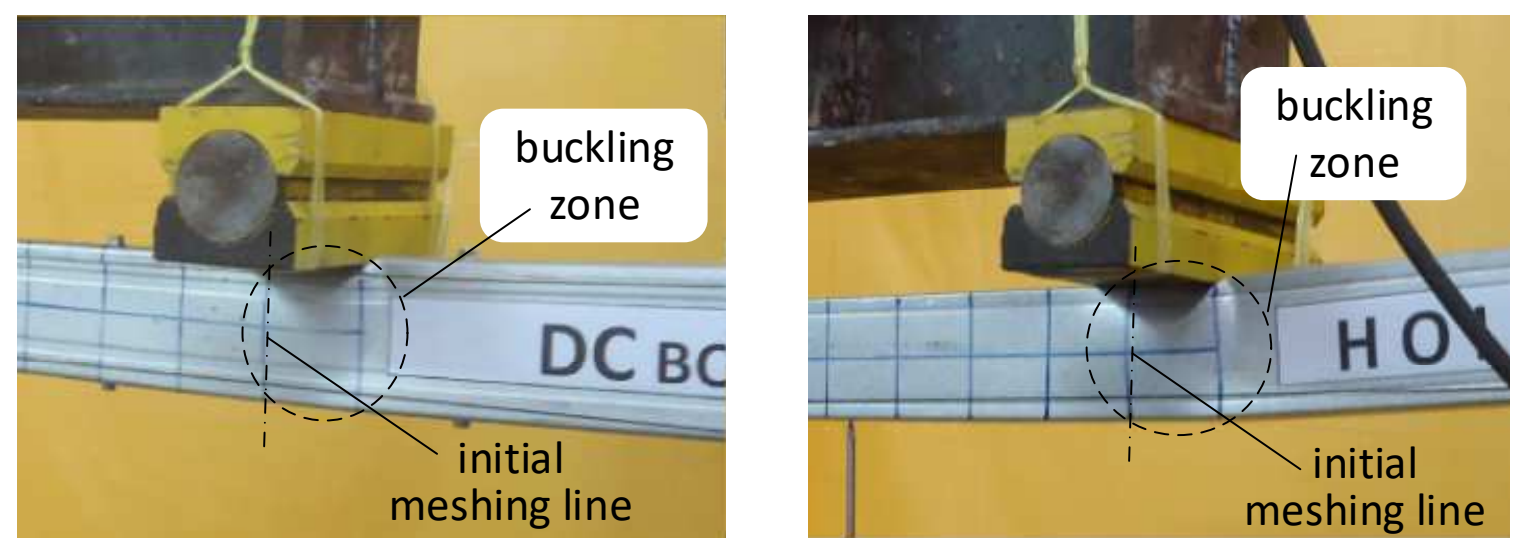

Fig. 4 Permanent local buckling on DC-Box Section (left) and Hollow Section (right) 

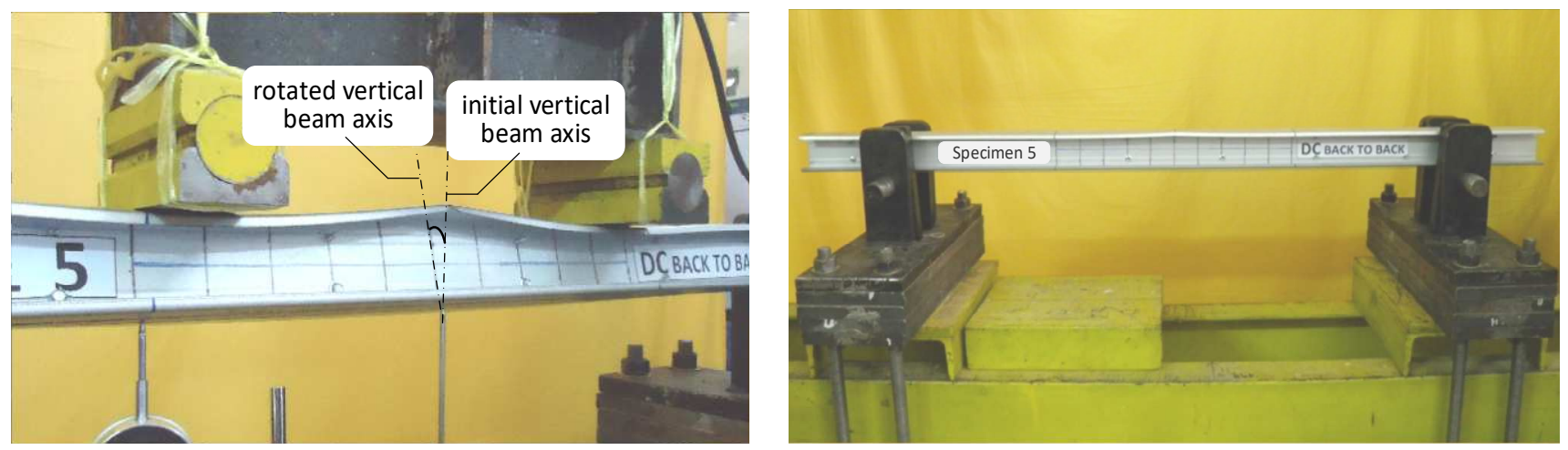

Fig. 5 Elastic lateral buckling on DC-I: deformed beam (left) and beam returned to its original position after load removed (right)

Different buckling mode was found on the DC-I beam which two channel sections combined in back-to-back position (Fig. 5). Lateral torsional buckling occurred on the beam. The section was rotated and displaced laterally; maximum deformation occurred at the mid-span. A slight buckling on the lip part of the flange at the mid-span was observed. Similar to DC-Boxes and Hollow sections, the DC-I beam's resistance dropped significantly when the lateral torsional buckling initiated. However, the deformation was not permanent because the specimen returned to the original position when all equipment removed, except a small spot on the lip part of the flange at the mid-span which experienced buckling.
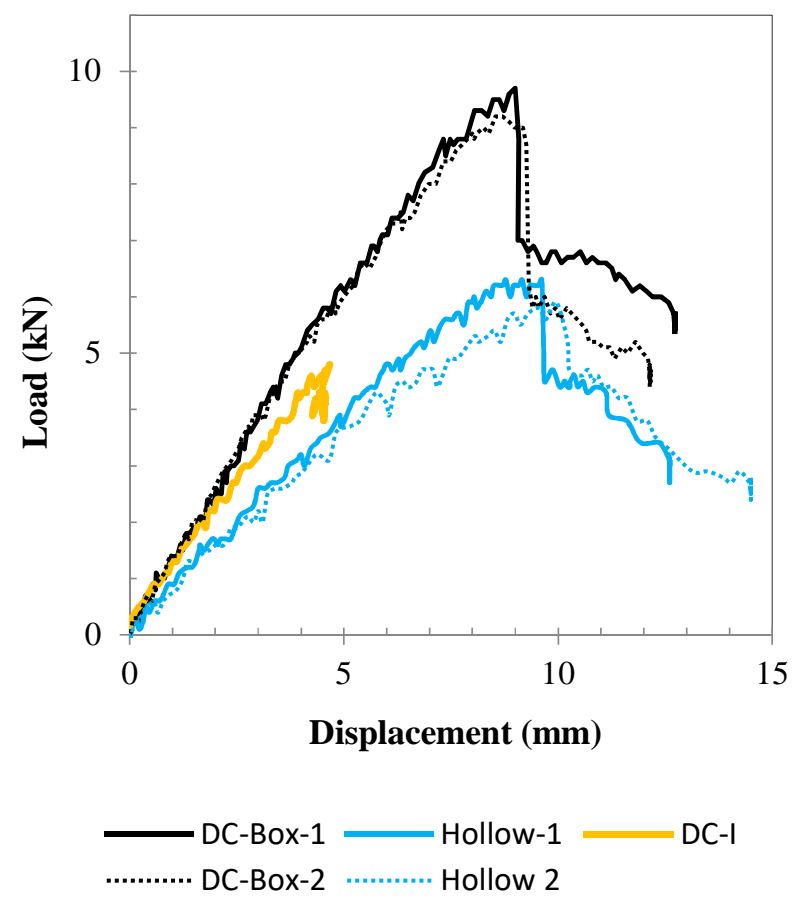

Fig. 6 Load-displacement curves of each specimen

Load-displacement curves showing the maximum resistance for each specimen are presented in Fig. 6. The displacement plotted in the graph was the data obtained from the LVDT's measurement which was placed in the mid-span of the beam.
In general, the load-displacement curves were linear in the beginning until the maximum load reached. Curve gradients for DC-Box and DC-I were almost identical until $2 \mathrm{~mm}$ displacement. After this point, the specimen of DC-I had less curve gradient than DC-Box. However, all double channels' curves lied above the Hollow section ones.

The maximum loads for two DC-Box specimens and one DC-I specimen were $9.7 \mathrm{kN}, 9.2 \mathrm{kN}$, and $4.8 \mathrm{kN}$ respectively. Meanwhile, the Hollow sections reached the maximum load at $6.3 \mathrm{kN}$ and $5.9 \mathrm{kN}$. Regarding deflection at the maximum load, the DC-Box specimens and the Hollow section displaced vertically within the range of $9.0-9.9 \mathrm{~mm}$; the DC-I specimen that lateral torsional buckling occurred, had $4.8 \mathrm{~mm}$ of displacement.

\section{B. Comparison to Analytical Calculation}

1) Curve Gradient in the Elastic Region: A classical method has been used to determine the displacement at the mid-span of a simple beam subjected by two point loads as illustrated in Fig. 2. This method is valid for small displacement in the elastic region, for where the response of all specimens before the maximum load existed. After rearrangement the formula adopted from [15], a relation between total load (P) and displacement (d) can be determined as follows::

$$
P=\left(\frac{48 E I_{x}}{3 a L^{2}-a^{3}}\right) d
$$

where $\mathrm{E}$ is the elastic modulus, $\mathrm{I}_{\mathrm{x}}$ is the moment of inertia of the section concerning an axis which perpendicular to the applied load, a is the distance between point load and support and $\mathrm{L}$ is the beam span. The value inside the bracket in (1) will be equivalent to the curve gradient in the elastic region in Fig. 6. It can be seen that the curve gradient only depends on the moment of inertia of the section since the remaining variables $(\mathrm{E}, \mathrm{a}, \mathrm{L})$ are same.

As given in Fig. 1, the moment of inertia Ix for DC-Box and DC-I are slightly different because combination two channel sections to be DC-Box and DC-I will keep the Xaxis of the sections almost in the same position. Therefore, by using Eq. (1), load-displacement curves for DC-Box and DC-I should also be similar. 


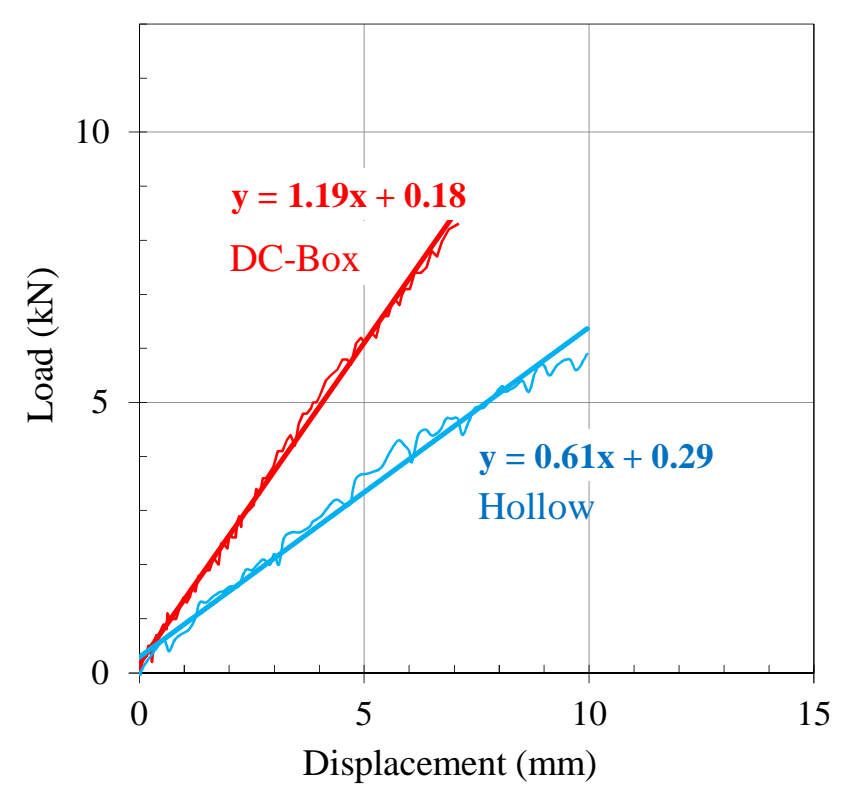

Fig. 7 Curve gradients in the elastic region for DC-Box and Hollow section

In Fig. 7 a linear regression for each representative curve of DC-Box and Hollow section are shown respectively. It is noted that DC-I's curve is omitted for clarity. The curve gradient for the Hollow section is about a half of double channel sections one. Hence, for the same load value, the Hollow section will displace about two times more than the displacement of the double channel sections. By using Eq.1, we can calculate the curve gradients for each specimen. The calculations and comparison to experimental tests are given in Table 2.

TABLE II

CURVE GRADIENT (IN KN/MM)

\begin{tabular}{|c|c|c|c|}
\hline Specimen & Analytical & Experimental & Difference \\
\hline DC-Box & 1.29 & 1.19 & $7.8 \%$ \\
\hline DC-I & 1.29 & 1.05 & $18.6 \%$ \\
\hline Hollow & 0.58 & 0.61 & $5.2 \%$ \\
\hline
\end{tabular}

Good agreements between experimental results and analytical calculations were achieved for Hollow and DCBox section, i.e., $5.2 \%$ and $7.8 \%$ of differences, respectively. Meanwhile, for the DC-I section, Eq.1 estimated the curve gradient $18.6 \%$ more than the experimental result.

2) Bending Capacity of the Beam: The maximum load in the load-displacement curves were utilized to determine bending capacity of each beam specimen. For this purpose, the shear force which was equal to $0.5 \mathrm{P}$ was multiplied by $385 \mathrm{~mm}$ of the shear span length to obtain the bending capacity of the beam. On the other hand, formulae in the Indonesian National Standard for Light Gauge Steel [16] which was adopted from Australian/New Zealand Standard for Cold-formed Steel Structures [17] were used to calculate the nominal moment of the beam. The nominal moment of the beam shall be taken the minimum value of Nominal Section Moment Capacity $\left(\mathrm{M}_{\mathrm{s}}\right)$ and Nominal Member Moment Capacity $\left(\mathbf{M}_{\mathrm{b}}\right)$, i.e.

$$
\begin{aligned}
& M_{s}=Z_{e} f_{y} \\
& M_{b}=Z_{c} f_{c}
\end{aligned}
$$

Where:

$\mathrm{Z}_{\mathrm{e}}$ : effective section modulus calculated with the extreme compression or tension fiber at $\mathrm{f}_{\mathrm{y}}$,

$\mathrm{Z}_{\mathrm{c}}$ : effective section modulus calculated at a stress $\mathrm{f}_{\mathrm{c}}$ in the extreme compression fiber,

$f_{y}$ : yield stress

$f_{c}$ : critical stress, defined as critical moment divided by full unreduced section modulus for the extreme compression fiber

Both effective section modulus $Z_{e}$ and $Z_{c}$ in (2) and (3) were equal to elastic modulus $S_{\mathrm{x}}$ for all sections used in this study; $S_{x}$ refers to values given in Fig. 1 . Thus, only critical stress fc remains the variable.

Experimental results and analytical calculations are summarized in Table 3 . The bending capacity of the Hollow section obtained from the experimental test differed $18 \%$ from the calculated moment capacity. Following the calculation procedures, it was obtained that the critical stress fc was equal to the yield stress $f_{y}$. Nominal Section Moment Capacity $\left(\mathrm{M}_{\mathrm{s}}\right)$ and Nominal Member Moment Capacity $\left(\mathrm{M}_{\mathrm{b}}\right)$ will then be identical. The same condition was found for the DC-Box for that the critical stress was equal to the yield stress. The deviation between experimental test and calculation was significant by $33 \%$.

TABLE III

BENDING CAPACITY OF BEAM (IN KN.M)

\begin{tabular}{|c|c|c|c|}
\hline Specimen & $\mathbf{M}_{\text {exp }}$ & $\mathbf{M}_{\text {cal }}$ & Deviation* \\
\hline DC-Box 1 & 2.01 & 2.95 & $33 \%$ \\
DC-Box 2 & 1.92 & & \\
\hline DC-I & 1.07 & 2.60 & $59 \%$ \\
\hline Hollow-1 & 1.36 & 1.62 & $18 \%$ \\
Hollow-2 & 1.28 & & \\
\hline
\end{tabular}

* Average experimental moment was used

For the DC-I beam, the calculated critical stress $f_{c}$ was less than the yield stress because the lateral torsional buckling was identified; the critical stress was $468.7 \mathrm{MPa}$ compare to 572.5 MPa yield stress. This critical stress reduced the nominal moment of the DC-I beam to be $2.60 \mathrm{kNm}$. However, the experimental result was still $59 \%$ of the calculation.

Analytical formulae provided in North American Specification [18] yielded similar results for bending capacities of the three types of specimens. The formulae in this code were presented in the stress term instead of the moment capacity one. However, all the steps had the same principle as determined in [16] and [17].

3) Post-buckling resistances: The resistance for the DCBox right after local buckling occurred was about $67 \%$ of its maximum one and the Hollow section kept $74 \%$ resistance 
after passing the peak. The resistance was continuously decreased for further loading. Meanwhile, the DC-I section almost lost its resistance when lateral torsional buckling initiated.

\section{Discussion}

1) Effect of section geometry: Two channel sections combined in the different positions are have similar main section properties, e.g., a moment of inertia and elastic section modulus of their strong axis. However, obvious responses were observed during the experimental tests. Permanent local buckling occurred on the DC-Box section and elastic lateral torsional buckling on the DC-I section (Fig. 8). Although the DC-I section had a better moment of inertia of its weak axis than the DC-Box section, it did not contribute well to resist the lateral-torsional deformation. Closed section form of the DC-Box helped more effective to prevent the lateral-torsional deformation. The failure loads for the DC-Box section was about two times compared to the later one.

Comparing two closed section: the DC-Box and the Hollow section, the similar response was found. Both sections failed due to permanent local buckling occurred on the top flange and the web.

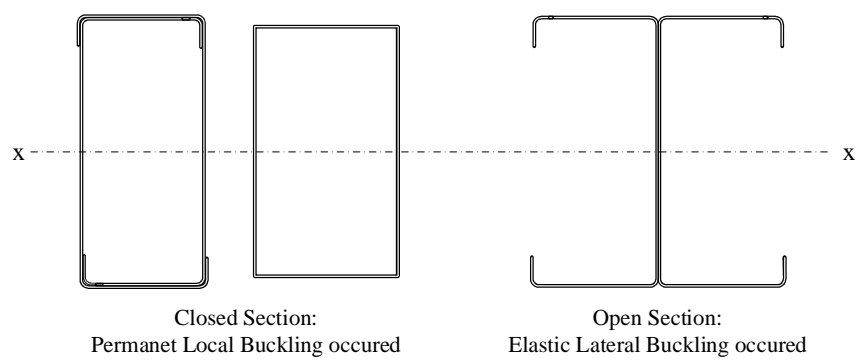

Fig. 8 Different section geometry caused an apparent response of structures during the test until the ultimate condition reached

2) Reduction factor for geometric properties and bending capacity: Regarding section properties of the combined channels, the elastic region of load-displacement curves were analyzed. Gradient curve of the experimental curves was lower than analytical gradient curve. This discrepancy was probably due to an assumption in a calculating moment of inertia of the combined channel sections. It was assumed that the combined channel sections were a single entity that the thickness of the adjacent webs or flanges were double. Therefore, if this single entity was assumed, the moment of inertia of the combined channel sections should be reduced. Based on the experimental results, the reduction factor of 0.8 and 0.9 are proposed for DC-I and DC-Box sections, respectively.

It was obviously seen that permanent local buckling and elastic torsional buckling were significant factors preventing the beam achieve the higher bending capacity. For the closed sections: DC-Box and Hollow section, local buckling still occurred even though analytical calculation showed that these sections were not vulnerable to buckle. For the open section, i.e., DC-I, lateral torsional buckling occurred as expected by analytical calculation. However, the predicted bending capacity of the beam was still too high.
To overcome higher analytical bending capacity than the experimental result, it is suggested to use a moderate bending capacity by adding a reduction factor to the analytical formula. Using the limited data in this study, it is proposed to use a reduction factor of 0.4 in the formula for conservative results. In Fig. 9, the proposed reduction factor is denoted by straight red line, and all experimental data are now above the reduced bending capacity of the beam.

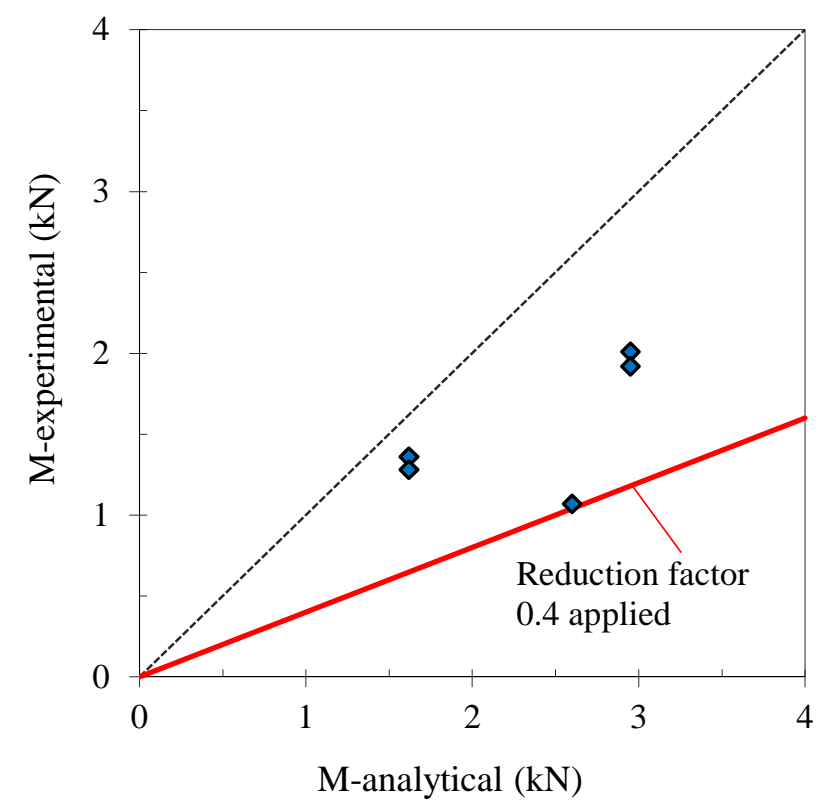

Fig. 9 Comparison between Experimental Results and Analytical Calculations

\section{CONCLUSION}

Experimental tests of the double channel and hollow sections of light gauge steel carrying a bending moment on their strong axis have been conducted in this study. It was found that section geometry: open or closed, was a significant factor in determining the type of ultimate condition of the beam as well as the maximum load. The open section, DC-I, was vulnerable to elastic lateral torsional buckling, while for the closed sections, i.e., DC-Box and Hollow, permanent local buckling occurred. Two channel sections which were combined as DC-Box could resist the ultimate load about two times higher than DC-I combination. Therefore, the earlier combination of two channel sections is suggested to be applied.

The experimental results were compared to analytical calculation, and it showed discrepancies within the range $18 \%-59 \%$. The reduction factor of 0.4 was proposed to be used in the analytical formula to obtain the conservative result of the bending capacity.

\section{ACKNOWLEDGMENT}

Part of this study was financially supported by Engineering Faculty, Andalas University for the financial year 2017 with contract number 008/UN.16.09D/PL/2017. 


\section{REFERENCES}

[1] W.W. Yu and R.A. LaBoube, Cold-Formed Steel Design, 4th ed. New Jersey, US: John Wiley \& Sons, 2010.

[2] S. Mohammad, M. M. Tahir, C.S. Tan, and P. N. Shek, "Experimental Investigation on Wide-Span Cold-Formed Steel Roof Truss System," Applied Mechanics and Materials, vols. 166-169, pp. 1304-1307, 2012.

[3] Y. Li, Z. Shen, X. Yao, R. Ma, and F. Liu, "Experimental Investigation and Design Method Research on Low-Rise ColdFormed Thin-Walled Steel Framing Buildings," Journal of Structural Engineering, vol. 139, no. 5, pp. 818-836, May 2013.

[4] D.H. Bondok and H.A. Salim, "Failure Capacities of Cold-Formed Steel Roof Trusses End-Connections," Thin-Walled Structures, vol. 121, pp. 57-66, Dec. 2017.

[5] C. Yu and B.W. Schafer, "Distortional Buckling Tests on ColdFormed Steel Beams," Journal of Structural Engineering, vol. 132, no. 4, pp. 1-14, Apr. 2006.

[6] N. D. Kankanamge and M. Mahendran, "Behaviour and Design of Cold-Formed Steel Beams Subject to Lateral-Torsional Buckling," Thin-Walled Structures, vol. 51, pp. 25-38, Feb. 2012.

[7] M. Anbarasu, "Local-Distortional Buckling Interaction on ColdFormed Steel Lipped Channel Beams," Thin-Walled Structures, vol. 98, Part B, pp. 351-359, Jan. 2016.

[8] L. Laím, J.P.C. Rodrigues, and H.D. Craveiro, "Flexural Behaviour of Beams Made of Cold-Formed Steel Sigma-Shaped Sections at Ambient and Fire Conditions," Thin-Walled Structures, vol. 87, pp. 53-65, Feb. 2015.

[9] S. Maduliat, M.R. Bambach, and X.L. Zhao, "Slenderness Limits for Cold-Formed Channel Sections in Bending by Experimental
Methods," Journal of Constructional Steel Research, vol. 76, pp. 7582, Sep. 2012.

[10] A. Awaludina, K. Rachmawatia, M. Aryatia, and A.D. Danastria "Development of Cold-Formed Steel-Timber Composite for Roof Structures: Compression Members," Procedia Engineering, vol. 125, pp. 850-856, 2015.

[11] I.S. Irawati, A. Awaludin, and N.P. Sebastian, "The Performance of Cold-formed Steel Long-span Roof Structure Combined with Laminated Timber: Cold-formed Steel-Laminated Timber Composite," Procedia Engineering, vol. 171, pp. 1242-1249, 2017.

[12] R. Kandasamy, R. Thenmozhi, and L. S. Jayagopal, "FlexuralTorsional Buckling Tests of Cold-Formed Lipped Channel Beams under Restrained Boundary Conditions," International Journal of Engineering and Technology, vol. 6, no.2, pp. 1176-1187, Nov. 2014.

[13] Y.H. Lee, Y. L. Lee, and C. S. Tan, "Experimental Investigation on Cold-formed Steel Beams under Pure Bending," Jurnal Teknologi, vol. 58, pp. 13-20, May 2012.

[14] Metals Test Methods and Analytical Procedures, ASTM Std. 03.01, 1991.

[15] B. Davison and G.W. Owens, Steel Designers Manual, 6th ed. Berkshire, US: The Steel Construction Institute, 2003.

[16] Indonesian National Standard for Cold-formed Steel Structures (in Indonesian), SNI 7971, 2013.

[17] Australian/New Zealand Standard for the Design of Cold-formed Steel Structures, AS/NZS 4600, 2005.

[18] North American Specification for the Design of Cold-Formed Steel Structural Members, AISI S100, 2007. 